\title{
ANALISIS SWOT DALAM PENGELOLAAN SUMBERDAYA MINERAL DAN BATUBARA INDONESIA SERTA PROSPEKNYA DALAM MENGHADAPI MASYARAKAT EKONOMI ASEAN (MEA)
}

\author{
SWOT Analysis on Indonesian Mineral and Coal Resources \\ Management and Its Prospects Dealing with ASEAN Economic \\ Community (AEC)
}

\author{
HARTA HARYADI \\ Puslitbang Teknologi Mineral dan Batubara \\ Jalan Jenderal Sudirman 623 Bandung 40211 \\ Telp. (022) 6030483, Fax. (022) 6003373 \\ e-mail: hartah@tekmira.esdm.go.id
}

\begin{abstract}
ABSTRAK
Menghadapi tantangan Masyarakat Ekonomi ASEAN (MEA), diperlukan sebuah kebijakan dan terobosan yang baru bagi Indonesia khususnya bagi sektor pertambangan mineral dan batubara sehingga memiliki daya saing yang tinggi dan mampu menguasai pasar, di antaranya peningkatan kemampuan teknologi, melakukan inovasi, dukungan lembaga keuangan, perbaikan infrastruktur dan logistik, pembangunan industri pendukung, peningkatan mesin pengolahan bahan baku, dukungan energi, ketersediaan informasi dan kebijakan ekspor produk yang bernilai tambah. Tujuan kajian adalah diperolehnya rumusan strategi sektor pertambangan mineral dan batubara Indonesia dalam menghadapi Masyarakat Ekonomi ASEAN (MEA) yang sudah berjalan sejak akhir tahun 2015. Metodologi kajian adalah dengan menganalisis data sekunder dan studi literatur menggunakan analisis Strength, Weakness, Opportunities and Threat (SWOT). Hasil analisis menunjukkan, strategi yang harus diambil sektor pertambangan mineral dan batubara Indonesia antara lain, strategi SO yaitu strategi dengan mendayagunakan sumberdaya manusia (SDM) yang berkualitas dan profesional serta penggunaan teknologi yang modern untuk memanfaatkan sumber daya dan cadangan mineral dan batubara yang dimiliki. Strategi ST, antara lain dengan mendayagunakan SDM yang berkualitas dan profesional serta penggunaan teknologi yang modern untuk menghadapi ancaman persaingan yang tinggi dan untuk menghadapi kekurangan input bahan baku akibat tidak adanya hambatan ekspor. Strategi WO, strategi dengan memperbaiki segala kelemahan, antara lain memperbaiki infrastruktur, mengatasi kekurangan energi untuk menghasilkan produk yang berdaya saing tinggi dalam rangka meraih peluang pasar yang besar dan untuk memasok bahan baku industri dalam negeri. Sedangkan strategi WT yaitu mempercepat pembangunan infrastruktur, pembangunan energi untuk menghasilkan produk yang berdaya saing tinggi untuk menghadapi ancaman persaingan yang tinggi dan untuk menghadapi ancaman kekurangan bahan baku industri di dalam negeri. Hasil analisis dapat dijadikan masukan kebijakan dalam upaya meningkatkan daya saing sektor ini dalam menghadapi sektor sejenis di antara negaranegara ASEAN lainnya.
\end{abstract}

Kata kunci: kekuatan, kelemahan, peluang, tantangan, Masyarakat Ekonomi ASEAN. 


\begin{abstract}
Facing the challenge of the ASEAN Economic Community (AEC), it requires a policy and a new breakthrough new for Indonesia, especially for mineral and coal mining that have high competitiveness and being able to dominate the market, including upgrading technology, innovation, support for financial institutions, improvement of infrastructure and logistics, the development of supporting industries, the increase in raw material processing machinery, energy support, availability of information and policy on the export of value added products. The objectiveof this assessment is to formulate Indonesian mineral and coal mining trategically in facing of the ASEAN Economic Community (AEC) which has been running since the end of 2015. Methodology study is by analyzing secondary data and literature study using analysis of Strength, Weakness, Opportunities and Threat (SWOT). The analysis results show that the strategies for the US mineral and coal mining sector Indonesia, among others, SO strategy is a strategy by utilizing qualified human resources and professional as well as the use of modern technology to exploit resources of mineral and coal reserves. ST strategies, by utilizing qualified human resources and professional as well as the use of modern technology to face the threat of high competition and a shortage of raw material inputs due to the absence of export barriers. WO strategy, a strategy to rectify all the weaknesses, such as improving infrastructure, overcome the lack of energy to produce products that are highly competitive in order to achieve a large market opportunity and to supply raw materials for industry in the country. While WT strategies that accelerate the development of infrastructure, energy development to produce products that are highly competitive to face the threat of high competition a shortage of raw materials in the domestic industry. The results of the analysis can be used as an input for policy to increase the competitiveness of the sectors in facing other ASEAN countries.
\end{abstract}

Keywords: strengths, weaknesses, opportunities, threat, ASEAN Economic Community.

\section{PENDAHULUAN}

Tujuan para pemimpin Association of South East Asian Nations (ASEAN) membentuk Masyarakat Ekonomi ASEAN (MEA) didasari dari keinginan untuk mentransformasikan negara ASEAN menjadi kawasan yang stabil, makmur, dan berdaya saing tinggi dengan tingkat pembangunan ekonomi yang merata serta kesenjangan sosial ekonomi dan kemiskinan yang semakin berkurang di antara negara-negara ASEAN (Heriawan, 2013). Dengan adanya MEA, ASEAN menjadi suatu kawasan dengan aliran bebas barang, jasa, investasi, dan tenaga kerja terampil, serta aliran modal yang lebih bebas (Joedo dan Widyasanti, 2013). Dengan berlakunya MEA menurut Widiastuti (2013), akan terjadi peningkatan persaingan sektor pertambangan mineral dan batubara di pasar domestik negaranegara anggotanya. Pengusaha sektor pertambangan mineral dan batubara yang kondisi usahanya tidak efisien sehingga memiliki daya saing rendah, akan sulit untuk bersaing memperoleh pasar bagi produknya. Bagi pengusaha yang tingkat produksinya efisien sehingga memiliki daya saing tinggi maka bisa menguasai pasar.

Selain itu menurut Purwanto (2013), bahan baku sebagai input akan banyak mengalir ke negara anggota MEA yang memberikan harga tinggi, akibatnya perusahaan-perusahaan yang tidak efisien dan tidak berdaya saing ini akan bertambah kesulitannya, akibat tingginya harga input bagi produknya.

Menurut Ellitan (2013), pada umumnya, MEA akan memberikan keuntungan ekonomi dalam negeri maupun negara-negara anggota ASEAN secara keseluruhan, antara lain :

- Tarif impor yang rendah/nol/tidak adanya pembatasan (kuota) dan hambatan impor lainnya sehingga akan meningkatkan daya saing di pasar domestik maupun pasar ekspor (karena harga-harga dari bahanbahan baku dan input lainnya yang diimpor menjadi murah);

- Perbaikan alokasi sumber daya produksi yang terbatas akan tersalurkan ke kegiatankegiatan ekonomi yang produktif;

- Akses ke barang modal/teknologi menjadi lebih baik dan lebih maju. Negara yang belum mampu mengembangkan teknologinya sendiri, tidak akan ketinggalan karena dengan mudah bisa didapat dari anggota negara MEA yang sudah mampu mengembangkan teknologinya;

- Setiap negara bisa memperluas pasarnya (pasar ekspor) bisa memperluas variasi produk yang dapat diproduksi di dalam negeri dengan berdasarkan spesialisasi; 
- Adanya pertumbuhan eksternalitas yang menguntungkan seperti peralihan pengetahuan, peralihan teknologi, peralihan manajemen, peralihan organisasi dan metode produksi yang lebih efisien.

Selain memberi keuntungan, MEA akan memberikan tantangan, antara lain : Terjadi kekurangan bahan-bahan baku atau input lainnya di pasar dalam negeri. Karena tidak ada hambatan terhadap ekspor bahan baku, maka ekspornya akan meningkat, sehingga perusahaan-perusahaan di dalam negeri akan mengalami kelangkaan bahan-bahan baku tersebut. Selain itu, akan menambah beban sosial yang tinggi bagi negara berkembang yang memiliki keterbatasan SDM, teknologi dan modal (Kepner dan Tragoe, 2010).

Untuk kasus Indonesia, dampak perdagangan bebas, khususnya MEA terhadap perusahaan di Indonesia berdasarkan data Badan Pusat Statistik (Badan Pusat Statistik, 2015) menunjukkan bahwa jumlah unit usaha perusahaan dan kontribusi output-nya terhadap pembentukan produk domestik bruto (PDB) terus bertambah setiap tahun, yang mengindikasikan bahwa terbukanya ekonomi Indonesia dari pasar MEA belum merugikan perusahaan-perusahan domestik. Khusus untuk sektor pertambangan mineral dan batubara, dengan terbentuknya MEA, merupakan suatu momentum yang penting untuk mewujudkan visi dan misinya, karena dapat memberikan peluang untuk memperluas pasar bagi produk industri dan jasa yang berbasis mineral dan batubara.

Menurut Tambunan (2013), permasalahan yang akan dihadapi oleh sektor pertambangan mineral dan batubara Indonesia dalam menghadapi MEA ini ada dua persoalan. Pertama, mampukah sektor ini bersaing dengan sesama produk sektor tersebut yang akan masuk ke pasar domestik dari negara MEA lainnya. Kedua, mampukah sektor ini memanfaatkan peluang yang muncul (menguasai pasar) dengan berlakunya pasar bebas MEA. Upaya-upaya sudah banyak dilakukan pemerintah untuk mendukung sektor ini, dengan dikeluarkannya Undang Undang No. 4 Tahun 2009 Tentang Pertambangan Mineral dan Batubara, yang mewajibkan seluruh pengusaha sektor pertambangan mineral melakukan pengolahan dan pemurnian sebelum diekspor, agar diperoleh manfaat ekonomi yang besar dari sektor tersebut bagi pengusaha, negara dan masyarakat, serta memiliki daya saing yang tinggi dipasar ekspor. Namun sampai saat ini sektor pertambangan Indonesia belum memperlihatkan kemajuan, ditandai dengan lambatnya para pengusaha di sektor pertambangan mineral membangun pabrik pengolahan dan pemurnian sebagai amanat UU tersebut, serta kinerja yang makin menurun ditandai dengan banyaknya perusahaan yang berhenti dari rencana kegiatannya. Sehingga diprediksi sektor pertambangan mineral Indonesia tidak akan mampu bersaing di pasar MEA atau paling tidak bisa bertahan di pasar dalam negeri terhadap persaingan yang semakin ketat dari barang-barang impor. Tantangan yang dihadapi sektor pertambangan mineral dan batubara akan semakin berat di pasar MEA, yang intinya di pasar tersebut tidak ada lagi hambatan terhadap arus barang dan jasa, manusia dan modal antara negara-negara anggota ASEAN.

Dalam menghadapi MEA, sektor ini akan menghadapi banyak perubahan dan ketidak pastian pada lingkungan perusahaan (internal) maupun di luar perusahaan (eksternal), sedangkan Pemerintah, khususnya Kementerian ESDM yang secara nasional bertugas mengelola sektor ini perlu merencanakan dan merumuskan strategi bersaing menghadapi negara-negara ASEAN lainnya (Mardhatillah, 2015).

Upaya peningkatan kinerja dan daya saing produk dan jasa sektor ini, khususnya di dalam menghadapi MEA, perlu didukung dengan strategi yang tepat sesuai dengan perubahan lingkungan strategis, sedangkan salah satu alat analisis untuk merumuskan strategi pencapaian sasaran tersebut adalah analisis SWOT (Suhartini, 2012). Dengan analisis SWOT ini diharapkan dapat dirumuskan berbagai alternatif strategi yang perlu dilakukan sebagai masukan dalam penyusunan kebijakan sektor ESDM.

\section{METODE}

Metodologi yang digunakan dalam penelitian ini adalah deskriptif kualitatif dengan melakukan pengamatan langsung atau observasi, wawancara dan dokumentasi ke beberapa Dinas ESDM dan beberapa 
perusahaan tambang, serta studi literatur dari berbagai jurnal yang terkait. Metode deskriptif merupakan metode yang digunakan untuk meneliti status kelompok, suatu obyek, suatu kondisi dan suatu sistem perencanaan serta peristiwa yang kemungkinan akan terjadi .

Dari hasil wawancara dengan seluruh Dinas Energi dan Sumber Daya Mineral (ESDM) dan beberapa perusahaan responden maka dapat diketahui faktor strategis internal (kekuatan dan kelemahan) \& faktor-faktor strategis eksternal (peluang dan ancaman). Di samping itu dari berbagai literatur diketahui faktor-faktor keunggulan pertambangan Indonesia yang melebihi anggota negara-negara MEA lainnya yang selanjutnya diintegrasikan ke dalam sebuah tabel data sehingga kelemahan dari anggota negara-negara MEA lainnya dapat diketahui.

Berdasarkan Rangkuti (2006), setelah indikatorindikator SWOT (Kekuatan, Kelemahan, Peluang dan Ancaman) ditentukan,

a. Langkah pertama menentukan bobot, rating, dan score bobot. Bobot ditentukan berdasarkan tingkat kepentingan atau urgensi penanganan dengan skala 1 sampai 4 ( 1 = tidak penting, 4 = sangat penting).

b. Langkah kedua menjumlahkan bobot kekuatan dan bobot kelemahan, sehingga diperoleh total bobot. Selanjutnya dihitung bobot relatif untuk masing-masing indikator dengan cara membagi masing-masing bobot dengan total bobot dari kekuatan dan kelemahan, sehingga hasil total nilai bobot relatif tersebut bila dijumlahkan menjadi 1 atau $100 \%$. Dengan cara yang sama dihitung bobot relatif untuk peluang dan ancaman, sehingga total nilai bobot tersebut menjadi 1 atau $100 \%$

c. Langkah ketiga adalah menentukan rating, yaitu analisis yang mempengaruhi organisasi. Dan langkah selanjutnya, bobot dikalikan dengan rating.

Nilai rating untuk Kekuatan \& Peluang diberi nilai 1 sampai 4 .

a. Diberi nilai 1 kalau indikator kinerjanya semakin menurun dibanding pesaing.

b. Diberi nilai 2 kalau indikator kinerjanya sama dengan pesaing utama.

c. Diberi nilai 3 atau 4, kalau indikator tesebut lebih baik dibanding pesaing. Semakin tinggi nilainya artinya kinerja indikator tersebut semakin baik dibanding pesaing utama.

Nilai Rating Kelemahan \& Ancaman diberi nilai 1 sampai 4 .

a. Diberi nilai 1 kalau indikator semakin banyak kelemahannya dibanding pesaing.

b. Diberi nilai 4 kalau indikator kelemahan semakin menurun dibandingkan pesaing. Artinya pemberian nilai rating untuk variabel kelemahan \& Ancaman berkebalikan dengan pemberian nilai rating untuk variabel kekuatan \& peluang.

Nilai Score Bobot diperoleh berdasarkan hasil nilai bobot dikali nilai rating.

a. Total nilai score untuk faktor internal atau kekuatan \& kelemahan (IFAS). Semakin total nilai score mendekati 1 , semakin banyak kelemahan internal dibandingkan kekuatannya. Semakin nilainya mendekati 4, semakin banyak kekuatannya dibandingkan kelemahannya.

b. Total nilai score untuk faktor eksternal atau peluang \& ancaman (EFAS). Semakin total nilai score mendekati 1 , semakin banyak ancamannya dibandingkan dengan peluang. Semakin total nilai score mendekati 4, artinya semakin banyak peluang dibandingkan ancaman.

Gabungan kedua kondisi internal dan eksternal ini, menurut Afrilita (2013) selanjutnya masukkan dalam Internal External Matrix (analisis keterhubungan/ keterkaitan dalam matriks SWOT), sehingga kita mengetahui posisi persaingan yang akan terjadi pada korporat, unit bisnis, maupun produk yang kita analisis. Berdasarkan posisi ini kita dapat menentukan strategi yang tepat untuk memenangkan persaingan dibanding anggota negara-negara MEA lainnya (Tabel 1).

\section{HASIL ANALISIS DAN PEMBAHASAN}

\section{Kondisi Internal dan Eksternal Sektor Pertambangan Indonesia Dalam MEA}

Berdasarkan data Direktorat Jenderal Mineral dan Batubara (2015), dalam menghadapi MEA, sektor pertambangan mineral dan batubara Indonesia memiliki kekuatan, yaitu sumber daya yang dimiliki yang besar dan beragam dibanding negara-negara anggota MEA lainnya. 
Malaysia dan Indonesia adalah penghasil timah dan bauksit yang besar di dunia. Sementara Indonesia dan Brunei penghasil minyak bumi dan gas yang cukup besar (Tabel 2).

Berdasarkan data Pusat Sumber Daya Geologi (2014), sumber daya dan cadangan mineral dan batubara Indonesia bukan saja lebih besar dari negara-negara MEA, bahkan berkelas dunia. Sumber daya dan cadangan timah (3,92 miliar ton \& 1,59 miliar ton), tembaga $(29,75$ miliar ton \& 5,49 miliar ton) dan emas $(8,70$ miliar ton \& 2,83 miliar ton $)$, masingmasing berada di posisi nomor 3 (tiga) terkaya di dunia sedangkan untuk nikel (5,76 miliar ton \& 3,20 miliar ton) menempat nomor 4 (empat) dunia. Sedangkan sumber daya dan cadangan batubara yang dimiliki Indonesia saat ini berjumlah 125, 28 miliar ton dan 32,36 miliar ton. Di samping mineral dan batubara, Indonesia juga memiliki sumber daya bahan galian non-logam, dan batuan yang sangat berlimpah (Pusat Sumber Daya Geologi, 2012) antara lain bentonit 615,19 juta ton, felspar 7,73 miliar ton, gamping 347,54 miliar ton, granit 57,90 miliar ton, kaolin 1,06 miliar ton, marmer 100,48 miliar ton, pasir kuarsa 18,15 miliar ton, andesit sebesar 78,15 miliar ton, trass sebesar 4,28 miliar ton, dolomit, sebesar 3,27 miliar ton, zeolit, 615,19 juta ton, bondclay sebesar 297,42 juta ton, basalt, 5,57 miliar ton, batu sabak sebesar 1,94 miliar ton, dasit 2,79 miliar ton, diorit slebesar 8,75 miliar ton, dan gabro peridotit sebesar 4,35 miliar ton.

Tabel 1. Analisis keterkaitan dalam matriks SWOT (internal, external matrix)

\begin{tabular}{|c|c|c|}
\hline \multirow{2}{*}{$\begin{array}{c}\text { FAKTOR EKSTERNAL } \\
\text { (EFAS/External factors analysis } \\
\text { strategic) }\end{array}$} & \multicolumn{2}{|c|}{$\begin{array}{c}\text { FAKTOR INTERNAL } \\
\text { (IFAS/Internal factors analysis strategic) }\end{array}$} \\
\hline & Strengths $(\mathrm{S})$ & Weaknesses (W) \\
\hline Opportunities (O) & $\begin{array}{l}\text { Strategi SO (Maxi-Maxi) } \\
\text { Mengembangkan suatu strategi } \\
\text { dalam memanfaatkan kekuatan } \\
\text { di lingkungan internal }(\mathrm{S}) \text { untuk } \\
\text { mengambil peluang }(\mathrm{O}) \text { dari } \\
\text { lingkungan eksternal. }\end{array}$ & $\begin{array}{l}\text { Strategi WO (Mini-Maxi) } \\
\text { Mengembangakan suatu strategi } \\
\text { dalam mengatasi kelemahan di } \\
\text { lingkungan inernal }(\mathrm{W}) \underline{\text { dengan }} \\
\frac{\text { memanfaatkan peluang }}{(\mathrm{O}) \mathrm{di}} \\
\text { lingkungan eksternal. }\end{array}$ \\
\hline Treats $(\mathrm{T})$ & $\begin{array}{l}\text { Strategi ST (Maxi-Mini) } \\
\text { Mengembangkan suatu strategi } \\
\text { dalam memanfaatkan kekuatan } \\
\text { di lingkungan internal (S) untuk } \\
\text { mengatasi ancaman }(\mathrm{T}) \text { di } \\
\text { lingkungan eksternal. }\end{array}$ & $\begin{array}{l}\text { Strategi WT(Mini-Mini) } \\
\text { Mengembangkan suatu strategi } \\
\text { dalam mengatasi kelemahan di } \\
\text { lingkungan internal }(\mathrm{W}) \text { dan } \\
\text { mengatasi ancaman }(\mathrm{T}) \mathrm{di} \\
\text { lingkungan eksternal. }\end{array}$ \\
\hline
\end{tabular}

Tabel. 2. Sumber daya tambang negara-negara ASEAN

\begin{tabular}{|c|c|c|}
\hline No. & Negara & Sumber Daya Tambang \\
\hline 1 & Indonesia & $\begin{array}{l}\text { Minyak bumi, gas, bauksit, nikel, tembaga, timah, bijih besi, batu } \\
\text { bara, emas, perak, zirkon, mangan, kobalt, seng, gamping, kaolin, } \\
\text { kuarsa, belerang, timbal, batu mulia dan intan. }\end{array}$ \\
\hline 2 & Malaysia & Minyak bumi, gas, bauksit, emas dan perak. \\
\hline 3 & Brunei Darussalam & Minyak bumi, gas. \\
\hline 4 & Filipina & Minyak bumi, gas, bijih besi, emas, perak, kobalt, seng dan mangan \\
\hline 5 & Thailand & Timah, batu mulia, batu bara, mangan dan wolfram. \\
\hline 6 & Laos & Batubara, gipsum, timah, belerang dan tembaga. \\
\hline 7 & Kamboja & Minyak bumi, batu mulia, mangan, fosfat, seng dan krom. \\
\hline 8 & Vietnam & $\begin{array}{l}\text { Minyak bumi, batu bara, emas, bijih besi, timah, fosfat, seng dan } \\
\text { krom. }\end{array}$ \\
\hline 9 & Myanmar & $\begin{array}{l}\text { Minyak bumi, gas, emas, timbal, batu bara, batu mulia, timah, } \\
\text { tungsten dan pasir kuarsa. }\end{array}$ \\
\hline 10 & Timor Leste & Minyak bumi, gas, emas dan marmer. \\
\hline 11 & Singapura & $====$ \\
\hline
\end{tabular}

Sumber : World Trade Organization (WTO), 2015 
Persaingan dan Pembagian Pasar (Market Share) MEA, khususnya produk-produk berbasis tambang berdasarkan data (WTO (2015), pada tahun 2015, pangsa pasar ekspor Indonesia di dunia hanya $0,9 \%$, lebih rendah dibanding negara-negara ASEAN lainya yaitu, Vietnam sebesar $1,0 \%$, Malaysia 1,2\%, dan Thailand sebesar $1,3 \%$. Pasar produk-produk berbasis tambang Indonesia, sebagian besar di ekspor ke China, Jepang, Korea Selatan, Taiwan, Amerika dan dari negara-negara tersebut Indonesia mengimpor barang-barang setengah jadi maupun jadi untuk memenuhi kebutuhan industri di dalam negeri (Tabel 3).

Menurut World Bank (2015), dalam perekonomian Indonesia memiliki modal cukup kuat dalam menghadapi MEA, yaitu pertumbuhan perekonomian Indonesia tahun 2014 sebesar $5,0 \%$, tahun 2015 sebesar 5,2\% dan tahun 2016 diprediksi sebesar 5,5\%. Pertumbuhan ekonomi Indonesia tahun 2016 lebih baik dibandingkan dengan Thailand $(4,0 \%)$,
Malaysia $(5,0 \%)$, Singapura $(3,4 \%)$ dan Brunei sebesar $2,7 \%$ (Tabel. 4). Sedangkan pertumbuhan selama selama 2010-2015 meningkat rata-rata sebesar 5,1\% (Badan Pusat Statistik, 2015).

Selain itu, menurut Badan Pembangunan dan Perencanaan Nasional (2015), perkem-bangan perekonomian nasional untuk periode 20162019 akan tumbuh rata-rata $6,2 \%$ per tahun. Pertumbuhan PDB dalam jangka pendek ini memberi gambaran perkembangan perekonomian nasional yang cukup optimis. Agar pertumbuhan dapat stabil, maka harus diikuti oleh peningkatan teknologi, infrastruktur, ketersediaan energi listrik yang memadai untuk mendukung berjalannya segala aktivitas perekonomian. Asumsi perekonomian menurut Bappenas tersebut merupakan modal yang kuat bagi Indonesia dalam menghadapi MEA/AEC, namun seluruhnya tergantung dari bagaimana cara pemerintah mengelolanya untuk diwujudkan menjadi hal yang nyata.

Tabel. 3 Pangsa pasar ekspor Indonesia terhadap perdagangan dunia

\begin{tabular}{lccc}
\hline \multirow{2}{*}{ Negara } & \multicolumn{2}{c}{$\%$ Pangsa pasar ekspor dunia } & \% Pertumbuhan ekspor \\
\cline { 2 - 4 } & 2014 & 2015 & 2015 \\
\hline China & 12,3 & 13,8 & $-2,9$ \\
Amerika Serikat & 8,5 & 9,1 & $-7,1$ \\
German & 7,9 & 8,1 & $-11,0$ \\
Jepang & 3,6 & 3,8 & $-9,5$ \\
Belanda & 3,5 & 3,4 & $-15,7$ \\
Korea Selatan & 3,0 & 3,2 & $-8,0$ \\
Taiwan & 1,7 & 1,7 & $-10,8$ \\
Thailand & 1,2 & 1,3 & $-5,8$ \\
Malaysia & 1,2 & 1,2 & $-14,6$ \\
Vietnam & 0,8 & 1,0 & $+7,9$ \\
Indonesia & 0,9 & 0,9 & $-14,8$ \\
\hline
\end{tabular}

Sumber : World Trade Organization (WTO), 2015

Tabel. 4 Pertumbuhan ekonomi negara-negara ASEAN

\begin{tabular}{clccc}
\hline No. & Negara & $2014(\%)$ & $2015(\%)$ & $2016 *(\%)$ \\
\hline 1 & Thailand & 0,7 & 3,5 & 4,0 \\
2 & Camboja & 7,0 & 6,9 & 6,9 \\
3 & Indonesia & 5,0 & 5,2 & 5,5 \\
4 & Laos & 7,5 & 6,4 & 7,0 \\
5 & Malaysia & 6,0 & 4,7 & 5,0 \\
6 & Myanmar & 8,5 & 8,5 & 8,2 \\
7 & Filipina & 6,1 & 6,5 & 6,5 \\
8 & Vietnam & 6,0 & 6,0 & 6,2 \\
9 & Singapura & 2,9 & 3,0 & 3,4 \\
10 & Brunei & 2,6 & 2,3 & 2,7 \\
11 & Timor Leste & 8,0 & 7,7 & 8,6 \\
\hline Sumber $:$ & World Bank, East Asia and Pacific Economic Update : Rebuilding
\end{tabular}


Berdasarkan data UNCTAD (2015), pada tahun 2014 menyatakan bahwa Indonesia merupakan negara paling menarik investor dan ekspansi bisnis di antara negara-negara anggota ASEAN lainnya (MEA) dan negara Asia Timur dengan menempati ranking no 4 sebagai tempat ekspansi dan investasi para investor dari seluruh dunia berada di bawah Singapura yang menempati rangking 3, Hongkong rangking 2 dan China rangking 1. Dana investasi asing secara langsung (foreign direct investment/FDI) masuk ke Indonesia, besarannya berdasar data United Nations Conference On Trade And Development (UNCTAD), sepanjang tahun 2014 mencapai $\$ 22$ miliar, dan berada di posisi no. 5 untuk kawasan Asia (Gambar 1).

Banyaknya investasi yang masuk ke Indonesia membutuhkan persiapan dari pemerintah, serta seluruh pemangku kepentingan di sektor pertambangan mineral dan batubara. Dibandingkan negara-negara MEA, kondisi saat ini pemerintah masih belum tegas dan jelas dalam menegakkan secara baik peraturan perundang-udangan, ditandai dengan tarik ulurnya Undang-Undang No. 4 Tahun 2009 tentang Pertambangan Mineral dan Batubara yang sampai saat ini masih berjalan di tempat. Dalam masalah penanaman modal asing (PMA) dan divestasi saham juga masih lemah, dampaknya dapat dilihat dengan banyaknya perusahaan tambang besar yang dikuasai oleh pihak asing. Semakin lama sumberdaya alam yang dimiliki Indonesia akan habis karena ciri khas tambang yang merupakan produk yang tidak terbarukan. Dalam masalah perkembangan teknologi, Indonesia masih jauh di bawah Singapura dan Malaysia, dimana kemampuan SDM menguasai teknologi di negara mereka terbukti sukses diimplementasikan dengan banyaknya inovasi yang memberikan hasil dan memberikan kepercayaan dari negara-negara yang mengadakan perdagangan dengan mereka.

Dalam masalah sosial dan keamanan negara kita masih di bawah Singapura, Malaysia dan Brunei. Indonesia hampir sama dengan Filipina dan Thailand lebih rentan terjadinya gejolak sosial dan situasi keamanan yang belum dapat dikendalikan terutama di daerah yang kaya akan sumber daya alam, seperti di Papua, dan Nangro Aceh Darussalam.
Namun dalam masalah lingkungan, berdasarkan ASEAN Senior Official Meeting on Mineral (ASOMM, 2015) yang berlangsung di Bali, Indonesia dianggap mempunyai kemampuan dan pengalaman yang melebihi negara-negara MEA dalam masalah pengelolaan lingkungan pertambangan, reklamasi, penutupan tambang dan rehabilitasi pasca tambang.

Berdasar data Badan Koordinasi Penanaman Modal (2015) mencatat total minat investasi ke Indonesia hingga Mei 2015 mencapai \$150 miliar. Dari jumlah itu, \$5,2 miliar diantaranya telah masuk kategori yang berdampak negatif karena sebagian besar berada di sektor substitusi impor dan industri padat karya, yang dapat menyaingi industri lokal. Dari data Institute for Development of Economics and Finance (INDEF, 2015) menyampaikan tren investasi dunia bergeser dari utara ke selatan. Jadi saat ini investor tidak lagi hanya berinvestasi di pasar modal negara-negara maju tetapi juga investasi di sektor riil.

Setelah China dan India kelebihan investasi, investor mulai mengarahkan investasi ke ASEAN. Dibanding Malaysia, Filipina dan Vietnam, Indonesia memiliki potensi yang paling baik sebagai sasaran investor. Sayangnya masalah bagi investor juga paling banyak terjadi di Indonesia seperti permasalahan birokrasi dan perizinan yang berbelit-belit, serta banyaknya pungutan liar di setiap perizinan. Untuk itu langkah pemerintah diperlukan untuk mengatasi persoalan ini, yaitu dengan berusaha memangkas jalur perizinan, agar mudah dan tidak berbelit-belit birokrasinya.

Global Competitiveness Index 2014-2015 berdasarkan World Economic Forum (2015), di level ASEAN, peringkat daya saing Indonesia ini masih kalah dengan tiga negara tetangga, yaitu Singapura yang berada di peringkat 2, Malaysia di peringkat 20, dan Thailand yang berada di peringkat ke-31. Namun demikian, posisi Indonesia ini masih mengungguli Filipina yang berada di peringkat 52, Vietnam di peringkat 68, Laos di peringkat 93, Kamboja di peringkat 95, dan Myanmar di peringkat 134 (Gambar 2). Penilaian peringkat daya saing global didasarkan pada 12 pilar daya saing, yaitu: pengelolaan institusi yang baik, infrastruktur, kondisi dan situasi ekonomi makro, kesehatan dan pendidikan dasar, pendidikan tingkat atas dan pelatihan, efisiensi 
pasar, efisiensi tenaga kerja, pengembangan pasar finansial, kesiapan teknologi, ukuran pasar, lingkungan bisnis, dan inovasi.

Lemahnya daya saing, khususnya sektor pertambangan mineral dan batubara disebabkan sampai saat ini, Indonesia masih menjual produk pertambangan mineral dan batubara dalam bentuk mentah, disebabkan program hilirisasi yang dicanangkan oleh pemerintah melalui Undang-Undang No. 4 tentang Pertambangan Mineral dan Batubara masih belum berjalan. Belum berjalannya program hilirisasi atau peningkatan nilai tambah dari produk mentah pertambangan mineral dan batubara, menurut para pengusaha disebabkan infrastruktur sebagai pendukung utama pembangunan pabrik pengolahan dan pemurnian belum memadai, begitu juga ketersediaan energi sampai saat ini belum mencukupi sehingga sulit bagi para pengusaha mewujudkan amanat Undang-Undang tersebut.

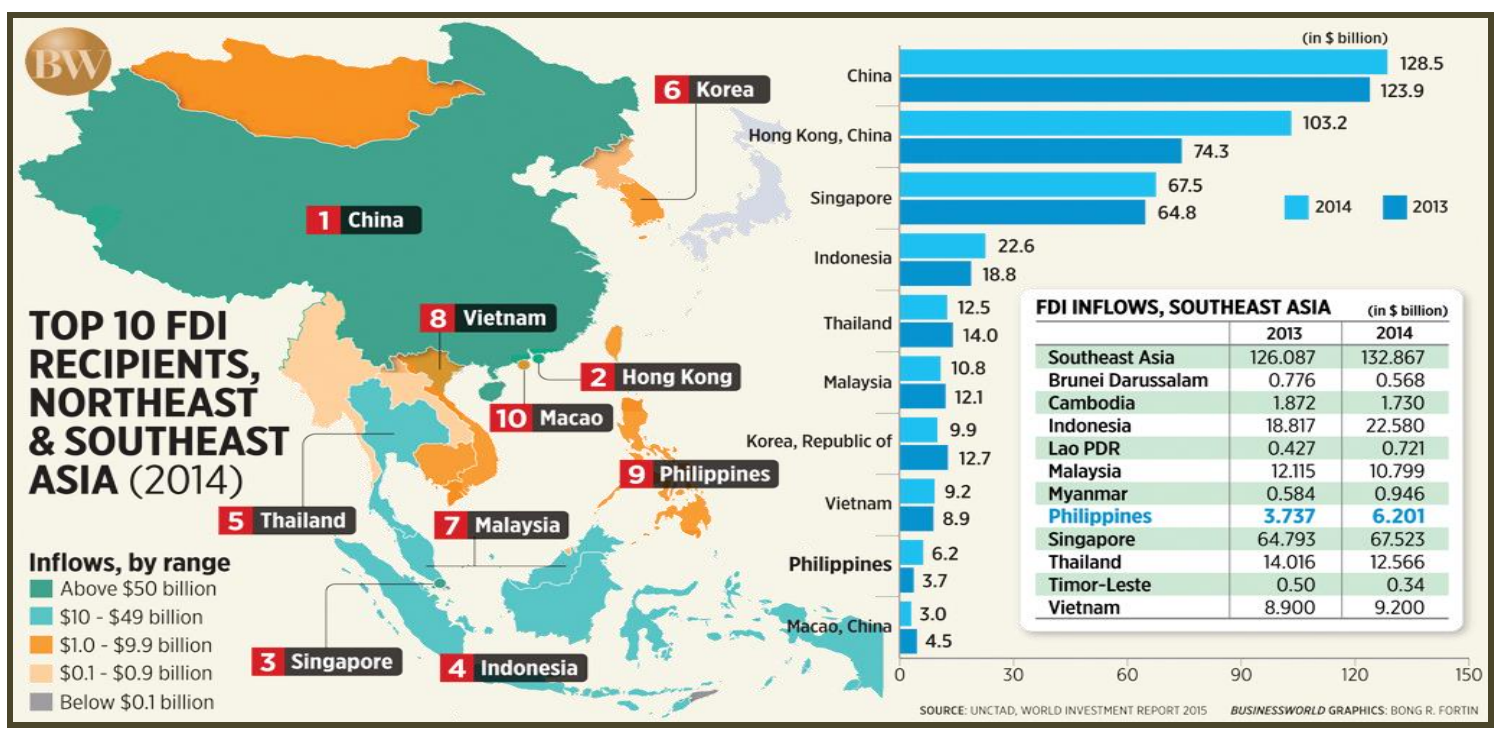

Sumber : Unctad, World Investment Report, 2015.

Gambar 1. Negara ASEAN yang menjadi tujuan investasi tahun 2013 - 2014

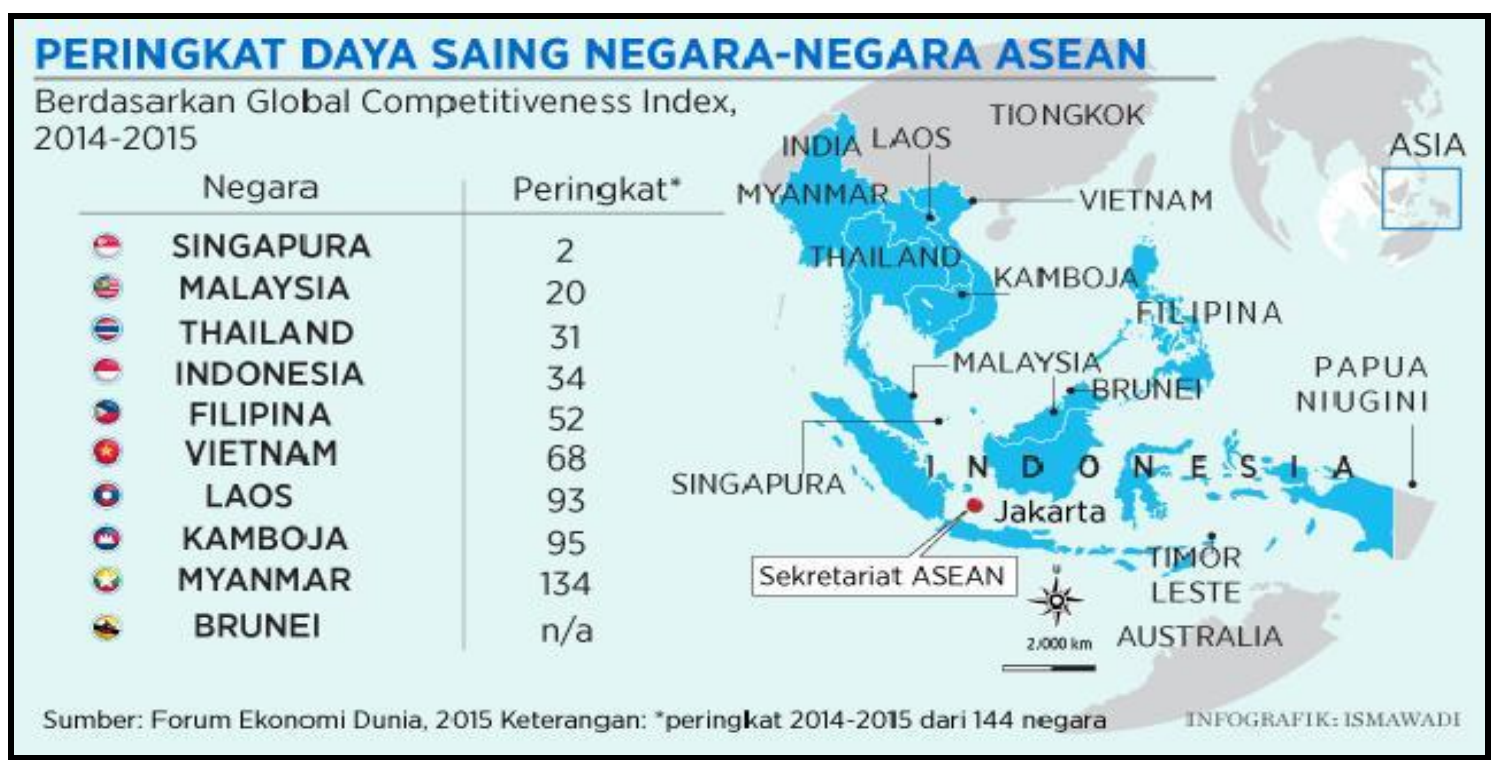

Sumber : World Economic Forum (Global Competitiveness Index Report, 2015)

Gambar 2. Daya saing Indonesia dibanding negara-negara ASEAN 2014-2015 
Di sisi lain, menurut data (The Economist, 2015), meskipun Indonesia memiliki peringkat daya saing no. 34 dan berada di bawah Singapura, Malaysia dan Thailand, namun dalam skor peringkat prioritas sebagai negara tujuan investasi, Indonesia menggungguli negara-negara tersebut dan merupakan negara tujuan Investasi no. 2 di kawasan Asia Pasifik setelah China.

Jumlah penduduk yang besar dan sebagian besar merupakan usia produktif merupakan dua faktor utama yang membuat Indonesia menjadi pasar potensial di mata investor. Data Population Reference Bureau (2014) menunjukkan Indonesia berada di peringkat keempat populasi terbesar dunia dengan ratarata pertumbuhan jumlah penduduk mencapai 21 persen dalam 10 tahun terakhir. Laporan World Population Pospect UNO (2014) telah memproyeksikan Indonesia akan menikmati "bonus demografi" dalam periode 2015-2030. Bonus demografi adalah kondisi di mana jumlah penduduk produktif lebih besar daripada jumlah penduduk non produktif, sehingga berpotensi mendorong tingkat konsumsi suatu negara, dan pada tahun 2014 jumlah penduduk Indonesia sudah lebih dari 244,47 dan pada tahun 2016 diperkirakan akan mencapai lebih dari 260 juta penduduk (Badan Pusat Statistik, 2015).

Pertumbuhan penduduk usia produktif itu juga akan secara signifikan ikut mendorong naiknya pendapatan per kapita. Data World Bank (2015) menunjukkan bahwa PDB per kapita atau pendapatan per kapita Indonesia di tahun 2014 sudah meningkat tiga kali lipat sejak tahun 2000. Peningkatan ini terbilang menonjol jika dibandingkan dengan beberapa negara ASEAN yang hanya tumbuh kurang dari dua kali lipat pada tahun 2000 pendapatan per kapita Indonesia hanya sebesar US\$ 790 dan pada tahun 2014 meningkat menjadi US\$ 3.592 melebihi Filipina (US\$ 2.614), Vietnam (US\$ 1.528), Myanmar (US\$ 835), Camboja (US\$ 934), dan Laos sebesar US\$1.446 (Tabel. 5).

Tabel 5. Pendapatan per kapita negara-negara MEA tahun 2014

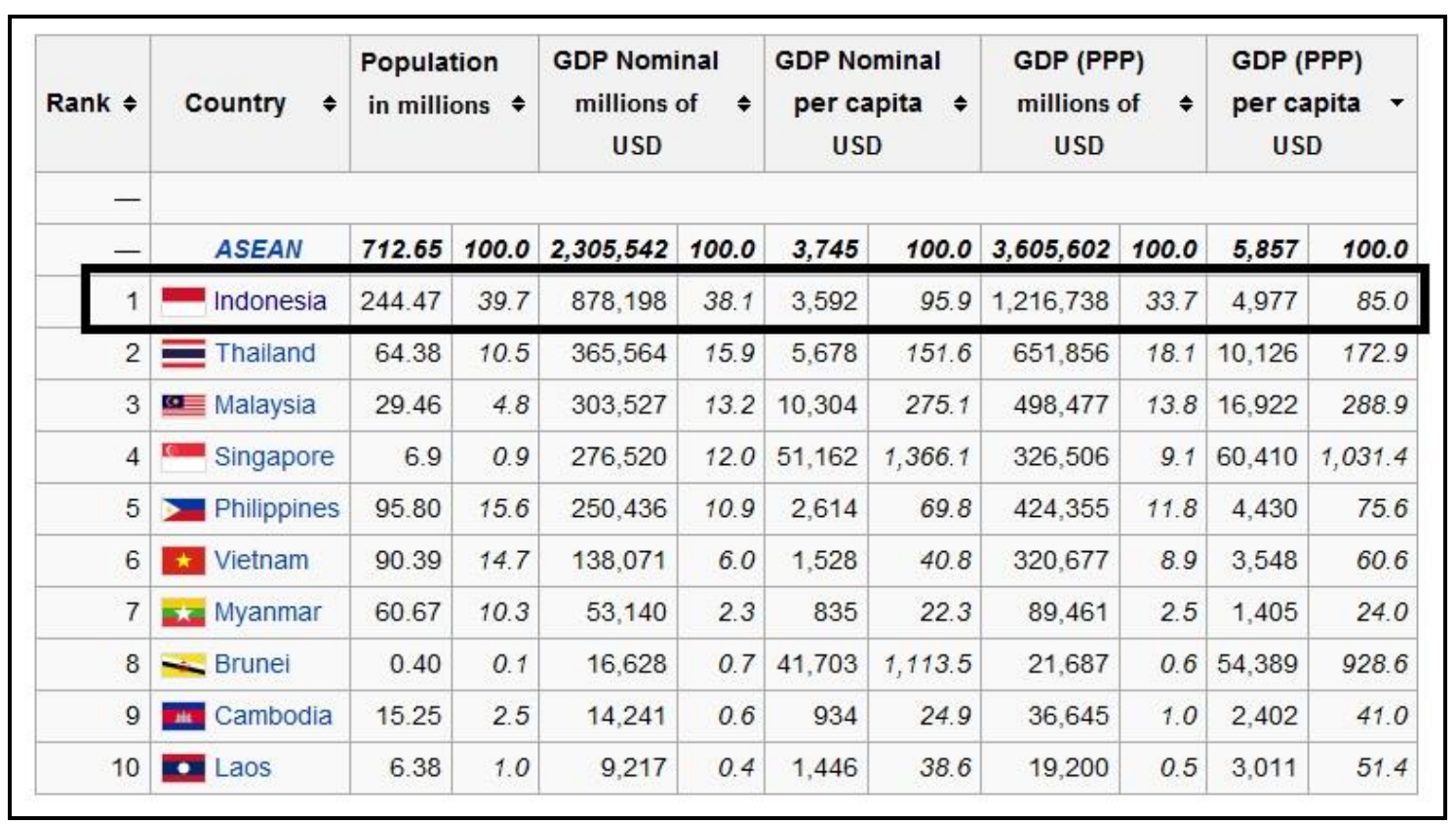

Sumber: World Bank, 2015. 
Untuk mewujudkan visi dan misi, khususnya dalam menghadapi Masyarakat Ekonomi ASEAN (MEA), Kementerian Energi dan Sumber Daya Mineral (KESDM) sebagai lembaga yang diberikan tugas untuk mengelola sektor pertambangan mineral dan batubara Indonesia, dituntut untuk melakukan analisis dalam rangka merumuskan strategi yang tepat. Salah satu model analisis yang digunakan adalah model SWOT yang memiliki matriks yang terdiri dari analisis lingkungan internal/internal factors analysis strategic (IFAS) berupa analisis faktor-faktor kekuatan dan kelemahan dari sektor pertambangan mineral dan batubara yang akan mendukung atau menghambat pelaksanaan misi dan juga menghambat pencapaian visi dalam menghadapi MEA. Selain itu, dilakukan juga analisis lingkungan eksternal/external factors analysis strategic (EFAS) berupa analisis faktor-faktor peluang dan ancaman dari sektor pertambangan mineral dan batubara yang akan membangun atau yang akan meruntuhkan pelaksanaan misi dan juga menghambat pencapaian visi perusahaan (Hartono, 2006).

Kedua analisis dilakukan untuk membantu sektor pertambangan mineral dan batubara menstrukturkan masalah serta untuk melihat kompleksitas permasalahan lingkungan sebagai strategi untuk memanfaatkan kekuatan untuk meraih peluang, sekaligus meminimalkan kelemahan dan mengatasi ancaman di lingkungan MEA (Choirunnisak, 2012).

Hasil perhitungan IFAS dan EFAS serta Matriks Analisis Keterkaitan SWOT ditunjukkan pada Tabel 6, 7 dan 8.

\section{KESIMPULAN DAN SARAN}

\section{Kesimpulan}

Dibanding seluruh anggota negara-negara Masyarakat Ekonomi ASEAN, Indonesia khususnya sektor pertambangan mineral dan batubara memiliki keunggulan yang bisa menjadikan sektor tersebut menguasai pasar dan memiliki daya saing yang tinggi dibanding sektor tersebut yang dimiliki oleh negara anggota lainnya. Di sisi lain, agar penguasaan pasar dan daya saing yang tinggi dapat dimiliki, maka dibutuhkan dukungan pemerintah mengatasi segala kelemahan di sektor tersebut, seperti perbaikan infrastruktur, dukungan energi yang memadai, perbaikan regulasi, pembenahan birokrasi serta penjagaan lingkungan sosial dan keamanan yang kondusif bagi kegiatan berusaha di sektor pertambangan mineral dan batubara.

\section{Saran}

Dari hasil analisis faktor internal, yaitu seluruh kekuatan dan kelemahan yang dimiliki sektor pertambangan Indonesia, serta analisis faktor eksternal seluruh peluang dan ancaman yang akan dihadapi sektor pertambangan Indonesia dari negara-negara anggota MEA lainnya, maka disarankan agar segala kekuatan yang dimiliki sektor pertambangan Indonesia agar lebih didaya gunakan dan ditingkatkan segala kemampuannya agar bisa meraih peluang dan menjadikan peluang menjadi sebuah kekuatan, sehingga memberikan kemungkinan bagi sektor pertambangan Indonesia untuk maju lebih cepat. Strategi yang harus diambil yaitu mobilisasi sumber daya yang merupakan kekuatan dengan mengatasi segala kelemahan untuk untuk meraih peluang dan menghilangkan ancaman, sehingga ancaman dan kelemahan menjadi sebuah peluang. 


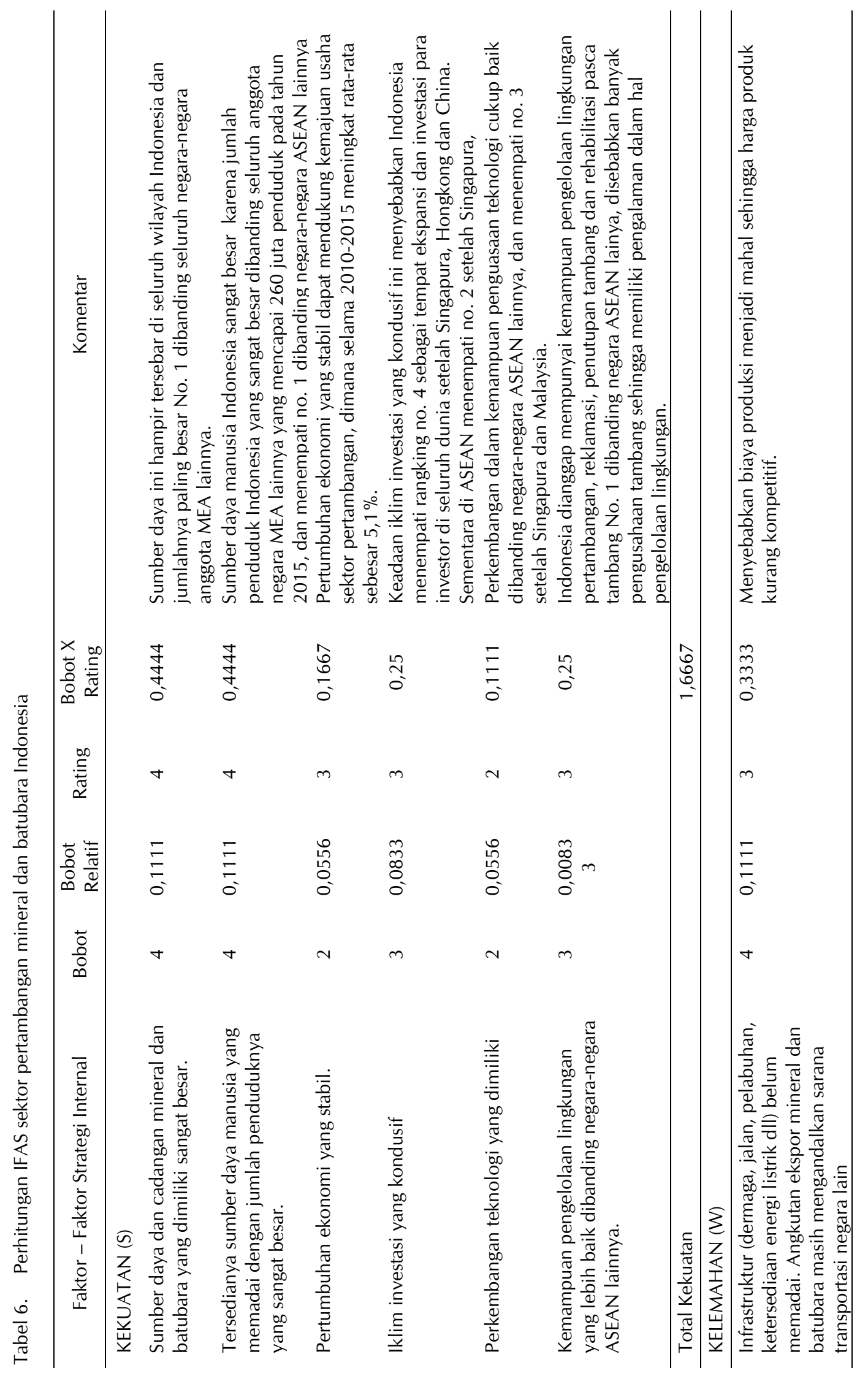




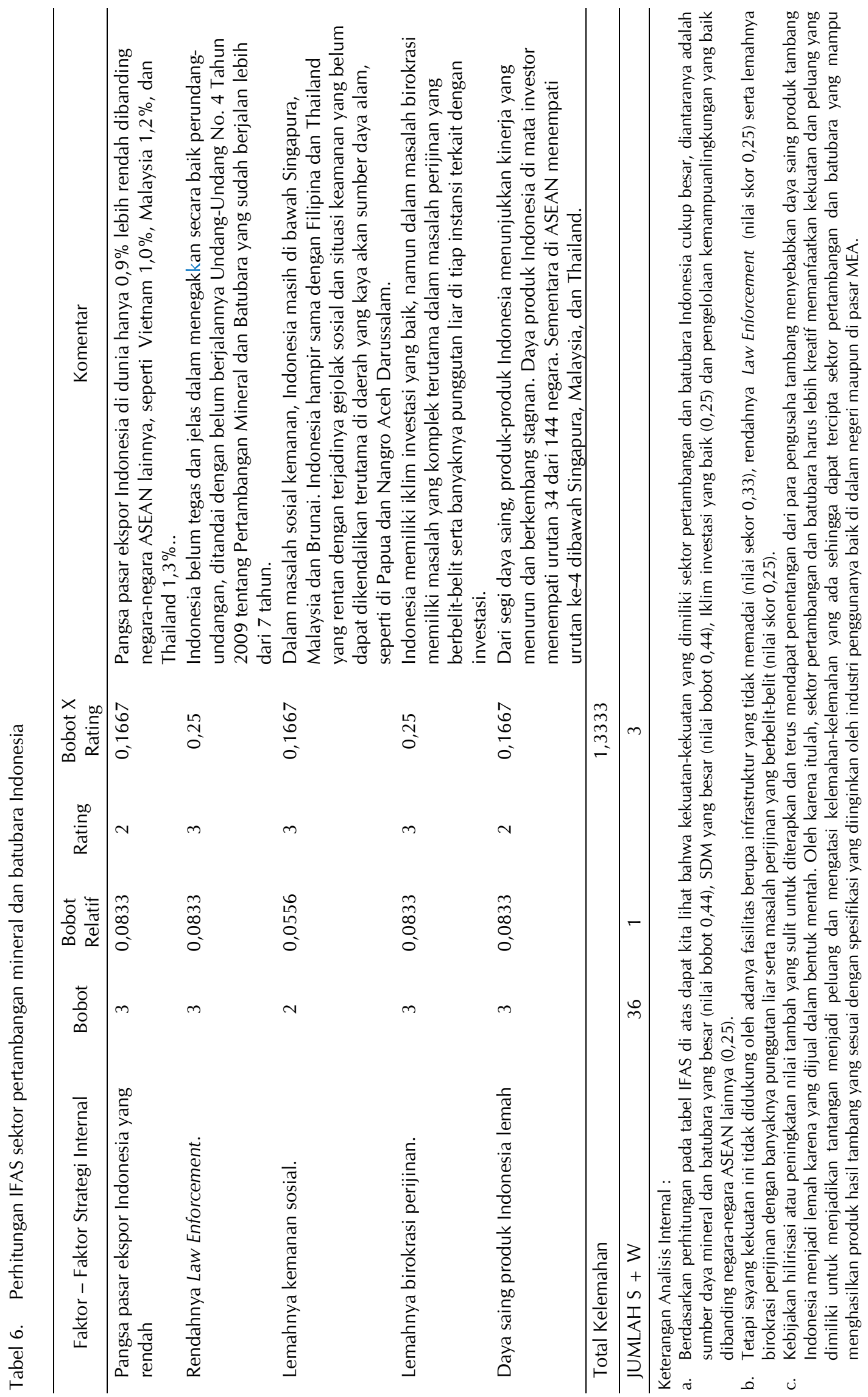




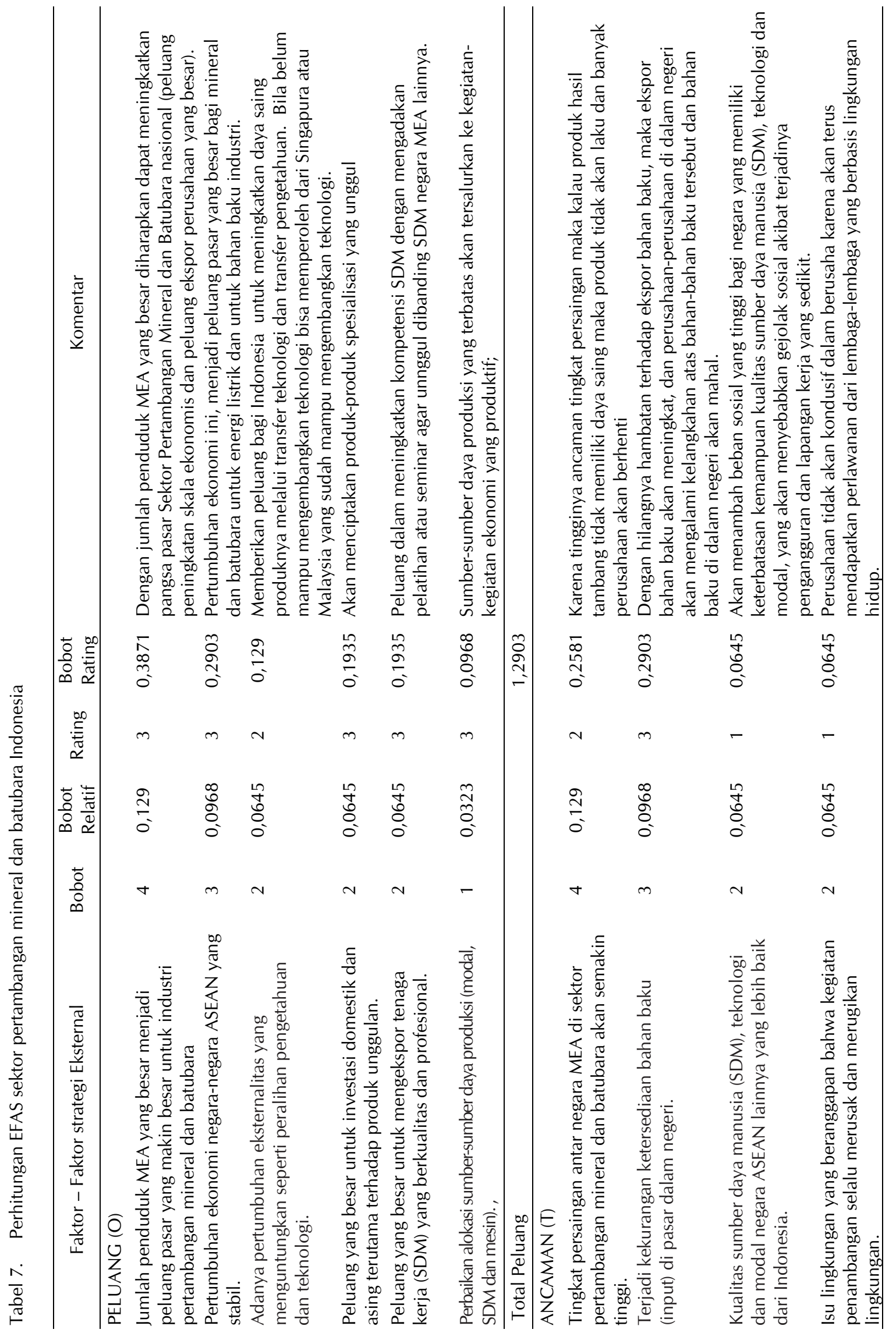




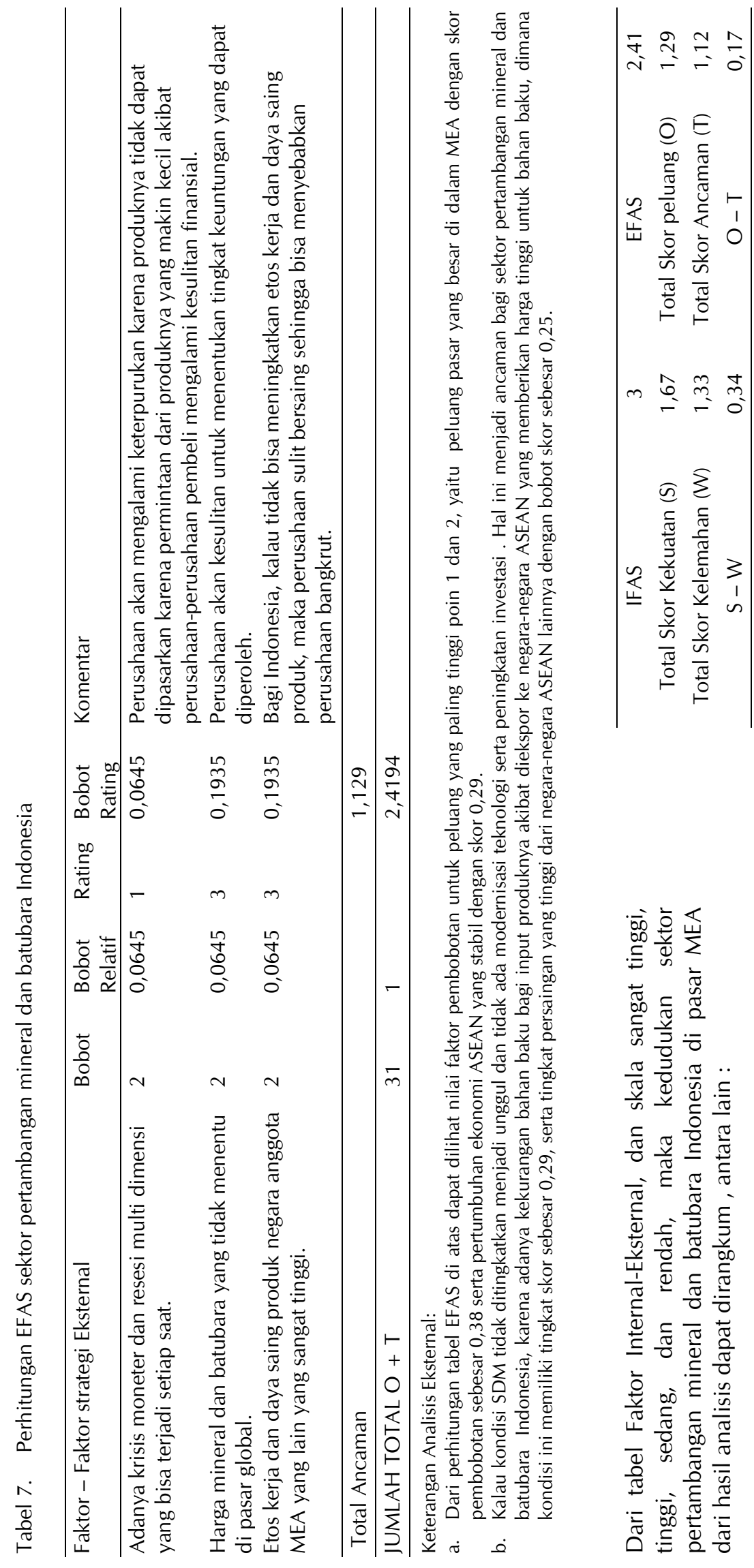




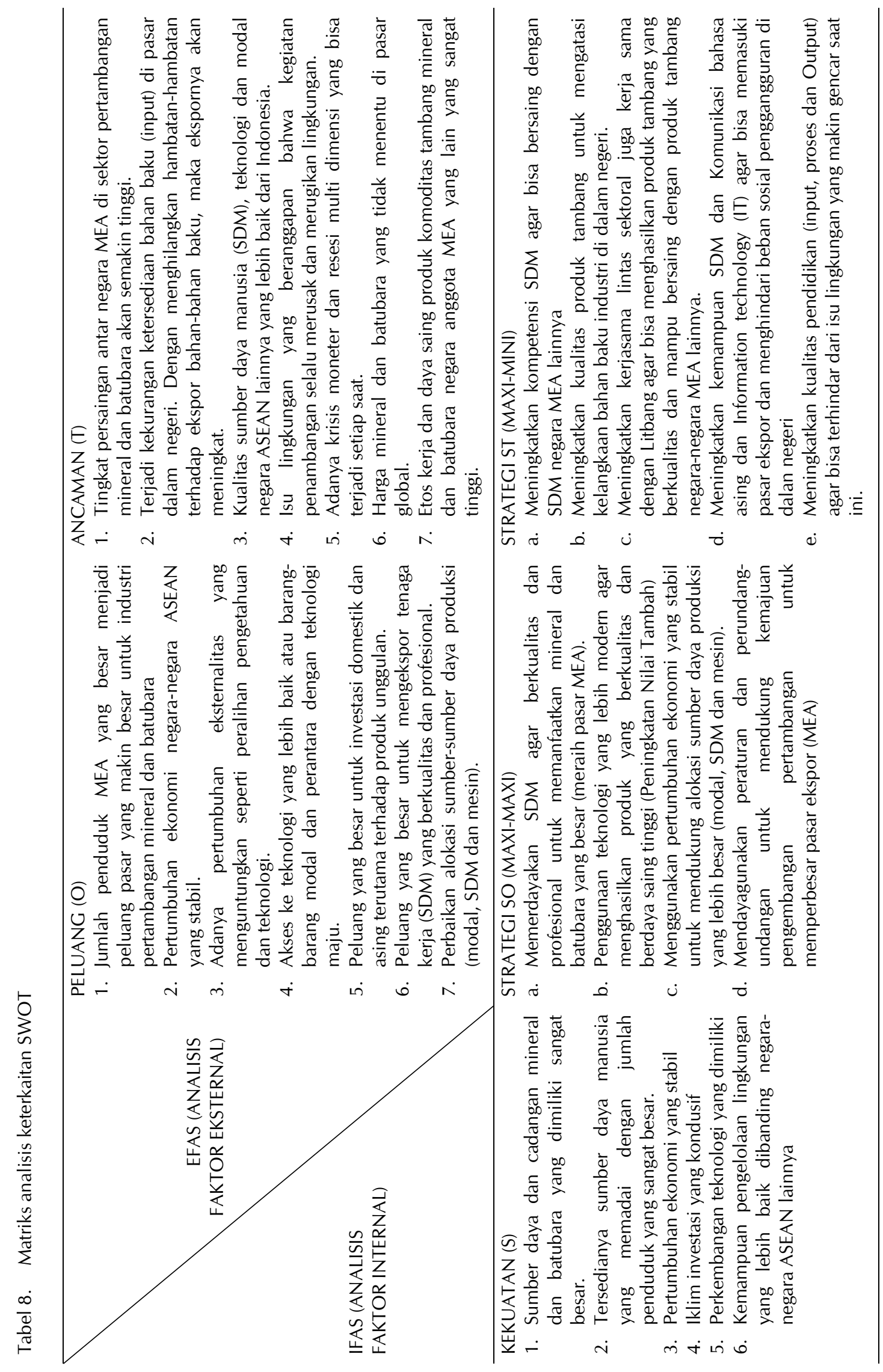




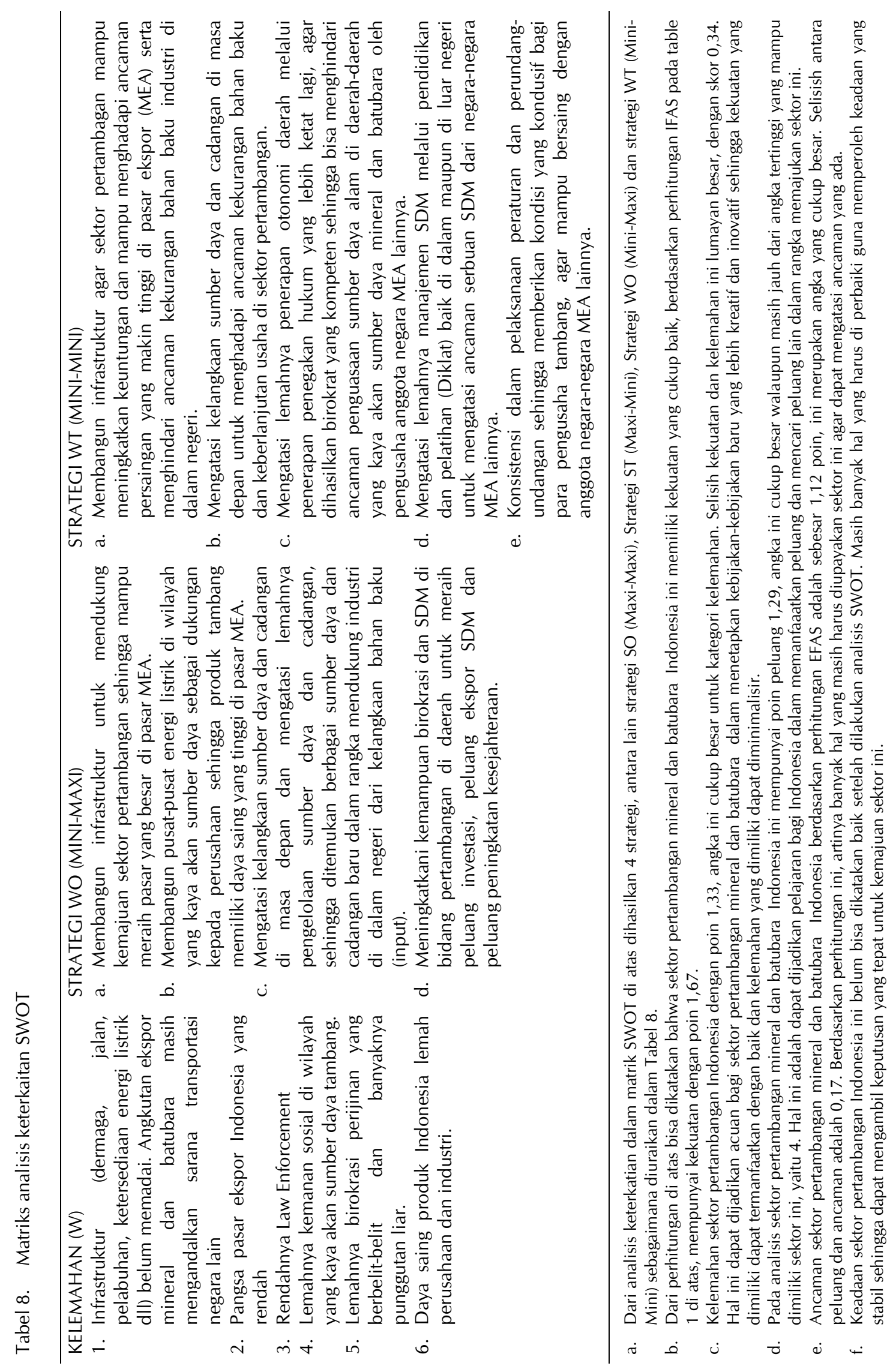




\section{UCAPAN TERIMAKASIH}

Dengan selesainya penelitian ini, penulis mengucapkan terimakasih kepada kontributor yang telah membantu memberikan data yang terkait dengan masalah sektor pertambangan mineral dan batubara, antara lain Dinas Pertambangan dan Energi Provinsi Kalbar, Provinsi Kalsel, Provinsi Kaltim, Provinsi Sultra, Provinsi NAD, Provinsi Jabar dan Provinsi Jateng. Di samping itu penulis juga mengucapkan terimakasih yang sebesar-besarnya kepada PT. Antam, PT. ICA, PT. Macika Mineral Industries, dan kepada Ikatan Sarjana Ekonomi Indonesia (ISEI), atas bantuan mengenai data permasalahan ekonomi baik nasional (domestik) maupun internasional (MEA) dan jurnaljurnalnya telah memperkaya hasil dari penelitian ini.

\section{DAFTAR PUSTAKA}

Afrilita, N. (2013) 'Analisis SWOT dalam menentukan strategi pemasaran sepeda motor pada PT. Samekarindo Indah di Samarinda', elournal Adminsitrasi Bisnis, 1(1), pp. 56-70.

ASOMM (2015) ASEAN Senior Official Meeting on Mineral (ASOMM). Bali.

Badan Koordinasi Penanaman Modal (2015) Investasi Penanaman Modal Dalam Negeri dan Penanaman Modal Asing. Jakarta: Badan Koordinasi Penanaman Modal.

Badan Pembangunan dan Perencanaan Nasional (2015) Perkembangan Ekonomi Indonesia dan Dunia. Jakarta: Penerbit Deputi Bidang Ekonomi Bappenas.

Badan Pusat Statistik (2015) Statistik Indonesia 2015. Jakarta.

Choirunnisak (2012) Penerapan analisis SWOT dalam strategi pemasaran produk tabungan pada BMI cabang pembantu Magelang. Sekolah Tinggi Agama Islam Negeri (STAIN) Salatiga.

Direktorat Jenderal Mineral dan Batubara (2015) Mineral and Coal Statistic.

Ellitan, L. (2013) 'Analisis lingkungan dan evaluasi keunggulan kompetitif perusahaan manufaktur Jawa Timur, Pendekatan studi kasus', in Siregar, H., Tambunan, M., Tulus Tambunan, Aviliani, Abimanyu, Y., Denni P. Purbasari, Hamid, E. S., Zulbainarni, N.,
Parningotan, F. S., Arsyad, L., and Triaswati, N. (eds) Seminar Nasional dan Sidang Pleno ISEI XVI. Jambi: Ikatan Sarjana Ekonomi Indonesia, pp. 254-278.

Hartono, J. (2006) Sistem informasi strategik untuk keunggulan kompetitif, Memenangkan persaingan dengan sistem teknologi informasi. Yogyakarta: Andi Offset.

Heriawan, R. (2013) 'Daya saing pertanian Indonesia menghadapi ASEAN Economic Community (AEC) 2015', in Siregar, H., Tambunan, M., Tambunan, T., Aviliani, Abimanyu, Y., Purbasari, D. P., Hamid, E. S., Zulbainarni, N., Parningotan, F. S., Arsyad, L., and Triaswati, N. (eds) Seminar Nasional dan Sidang Pleno ISEI XVI. Jambi: Ikatan Sarjana Ekonomi Indonesia, pp. 13-16.

Institute for Development of Economic and Finance, 2015. Tren Investasi Dunia Bergeser Dari Utara Ke Selatan. Institute For Development of Economic and Finance (INDEF), Jakarta, Oktober 2015.

Institute for Development of Economic and Finance, 2015. Memangkas Izin yang Berbelit-belit, Menunjang Kepastian Waktu Bagi Investor. Jakarta, 2015.

Joedo, P. W. M. and Widyasanti, A. A. (2013) 'Peningkatan daya saing daerah dalam menghadapi ASEAN Economic Community 2015', in Siregar, H., Tambunan, M., Tambunan, T., Aviliani, Abimanyu, Y., Purbasari, D. P., Hamid, E. S., Zulbainarni, N., Parningotan, F. S., Arsyad, L., and Triaswati, N. (eds) Seminar Nasional dan Sidang Pleno ISEI XVI. Jambi: Ikatan Sarjana Ekonomi Indonesia, pp. 25-45.

Kepner, C. H. and Tragoe, B. B. (2010) Manajer yang rasional. Jakarta: Lembaga Pendidikan dan Pembinaan Management \& Erlangga.

Mardhatillah, R. (2015) Analisis strategi pemasaran dengan analisis SWOT untuk meningkatkan penjualan pada PT. Forisa Nusapersada Padang. Universitas Taman Siswa Padang.

Population Reference Bureau (2014) World Population Data Sheet, Age Structure Has Changed Differently Across Region Between 1970-2014. Washington DC 20009.

Purwanto, B. (2013) 'Pola Pikir Baru Mengelola Sumber Daya Manusia Pada Era Knowledge Economy', in Manajemen Sumber Daya Manusia Berbasis Proses. Jakarta: Gramedia, p. 360 . 
Pusat Sumber Daya Geologi (2012) Laporan akhir pemutakhiran data dan neraca sumber daya mineral non-logam. Bandung.

Pusat Sumber Daya Geologi (2014) Laporan akhir pemutakhiran data dan neraca sumber daya mineral. Bandung.

Rangkuti, F. (2006) 'Reorientasi konsep perencanaan strategis untuk menghadapi abad 21', in Analisis SWOT Teknik Membedah Kasus Bisnis. Jakarta: PT. Gramedia Pustaka Utama, p. 200.

Suhartini (2012) 'Menentukan strategi pemasaran pada perusahaan', Jurnal MATRIK Teknik Industri Universitas Muhammdiyah Gresik, XII(2), pp. 1-8.

Tambunan, T. (2013) 'Masyarakat ekonomi ASEAN 2015, Peluang, tantangan, dan ancaman bagi UMKM Indonesia', in Siregar, H., Tambunan, M., Tambunan, T., Aviliani, Abimanyu, Y., Purbasari, D. P., Hamid, E. S., Zulbainarni, N., Parningotan, F. S., Arsyad, L., and Triaswati, N. (eds) Seminar Nasional dan Sidang Pleno ISEI XVI. Jambi: Ikatan Sarjana Ekonomi Indonesia, pp. 138-159.
The Economist (2015) 'Investing into Asia's reform landscape', in Asia Business Outlook Survey 2015, p. 420.

UNCTAD (2015) Top recipients of foreign direct invesments in Southeast and Northeast Asia in 2015.

Widiastuti (2013) 'Analisis SWOT keragaman budaya Indonesia', Jurnal Widya, 1(1), pp. 816.

World Bank (2015) 'Gross national income percapita 2015, more than 217 countries', in World Development Indicator Database, p. 625.

World Economic Forum (2015) Global competitivenes index report.

World Population Pospect UNO (2014) 'Interactive map and data visualization show population, Health and environment indicator for more than 200 countries', in World Population Data Sheet, p. 570.

World Trade Organization (2015) Pangsa pasar ekspor negara-negara terhadap pasar dunia. 